\title{
Role of Breast Ultrasound for the Detection and Differentiation of Breast Lesions
}

\author{
Helmut Madjar \\ Fachbereich Gynäkologie, Stiftung Deutsche Klinik für Diagnostik, Wiesbaden, Germany
}

Key Words

Breast cancer - Screening · Risk factor .

Dense breast . Ultrasound

\section{Summary}

Diagnosis of breast cancer has been widely improved since the development of high-resolution ultrasound equipment. In the past, ultrasound was only considered useful for the diagnosis of cysts. Meanwhile, it improves the differential diagnosis of benign and malignant lesions, local preoperative staging and guided interventional diagnosis. In dense breasts, mammography has limited sensitivity. Furthermore, women with dense parenchyma have a highly increased risk of breast cancer development. Ultrasound is useful to examine dense breast tissue. Recent studies have shown that the detection of small cancers with high-resolution ultrasound is increased by 3-4 cancers per 1,000 women without clinical or mammographic abnormalities. Furthermore, stage distribution is similar between mammographically and sonographically detected carcinomas. Ultrasound is routinely used for curative diagnosis, to overcome the limitations of mammography. However, within the mammographic screening in Germany, breast density is not considered as important. Ultrasound is only used if a suspicious lesion is detected by mammography. Interestingly, 2 years ago, a screening project started in Austria in which ultrasound is always added in cases of dense breasts. Preliminary data show that the detection of additional carcinomas is increased in the same order as shown in previous studies. Therefore, an improved cancer detection and differentiation can be expected with high-resolution ultrasound.

\author{
Schlüsselwörter \\ Mammakarzinom · Screening · Risikofaktor . \\ Brustparenchym, dichtes · Ultraschall
}

\section{Zusammenfassung}

Die Diagnostik des Mammakarzinoms hat durch die Entwicklung der modernen, hochauflösenden Mammasonografie bedeutende Fortschritte erzielt. Ursprünglich nur zur Differenzierung zwischen zystischen und soliden Raumforderungen eingesetzt, dient der Ultraschall mittlerweile zur Verbesserung der Differenzialdiagnostik zwischen gutartigen und bösartigen Tumoren, zum präoperativen lokalen Staging und zur interventionellen Diagnostik. Bei jungen Frauen und dichtem Brustparenchym weist die Mammografie eine erhebliche diagnostische Lücke auf. Außerdem haben Frauen mit dichtem Parenchym ein deutlich erhöhtes Krebserkrankungsrisiko. Ultraschall eignet sich sehr gut, um dichtes Brustgewebe zu untersuchen. Mehrere Studien zeigen, dass die hochauflösende Sonografie bei diesen Frauen zusätzlich 3-4 Karzinome pro 1000 Frauen mit unauffälligem klinischen und mammografischen Befund entdecken kann. Die Stadienverteilung ist dabei ähnlich günstig wie bei der mammografischen Früherkennung. In der kurativen Diagnostik wird der Ultraschall häufig eingesetzt, um die diagnostischen Probleme der Mammografie zu kompensieren. Im Rahmen des bundesweiten Mammografiescreenings wird die Brustdichte aber bislang nicht berücksichtigt. Der Ultraschall kommt nur zum Einsatz, wenn mammografisch ein verdächtiger Befund vorliegt. Interessanterweise wurde in Österreich vor 2 Jahren ein Screeningprojekt begonnen, in dem bei mammografisch dichter Brust Ultraschall eingesetzt wird. Die vorläufigen Auswertungen zeigen eine Steigerung der Karzinomerkennung in derselben Größenordnung wie in den früheren Studien. Daher ist eine Verbesserung der Brustkrebsdiagnostik durch die systematische Anwendung der Ultraschalldiagnostik zu erwarten.

\begin{tabular}{ll}
\hline KARGER & $\oplus$ c010 S. Karger GmbH, Freiburg \\
Fax +497614520714 & Accessible online at: \\
Information@Karger.de & www.karger.com/brc \\
www.karger.com &
\end{tabular}




\section{Introduction}

The value of ultrasound for breast cancer diagnosis has been a controversial topic for many years. Depending on equipment standards, clinical objectives and skills of medical professionals with different specializations, the interpretation of its role is variable. First experimental ultrasound examinations of the breast started 60 years ago, and it took about 30 years until technological development and acceptance by clinicians made it useful for clinical routine diagnosis. In the early studies, the use of ultrasound was limited to the differentiation of palpable cysts from solid lesions [1]. The development of modern equipment in the past 15 years has allowed for accurate detection and differential diagnosis of small lesions [2, 3]. In the ongoing debate about the use of ultrasound, Stavros et al. published the first large study with modern high-resolution breast ultrasound, using standardized diagnostic criteria for lesion differentiation [4]. At the same time, other groups started to evaluate the advantages of ultrasound in patients with dense breasts for the detection of non-palpable and mammographically occult lesions [5-7].

\section{Breast Cancer Detection}

The value of early breast cancer detection by mammography has been demonstrated by a number of randomized screening studies in different countries from 1960 to the 1990s. All these studies were performed with mammography alone or in combination with palpation. In the last 10 years, ultrasound has been employed as an adjunct to mammography whenever suspicious lesions were detected, in order to better characterize lesions and to decide whether an ultrasound-guided interventional procedure can be performed to confirm the diagnosis. This was established in the first edition of the German S3 guidelines for early detection of breast cancer in 2003 [8].

Apart from screening, ultrasound is widely used in daily practice in order to improve lesion detection and characterization. Several large studies have proven the possible role of ultrasound for cancer detection and differentiation [4-7, 9, 10]. However, despite the fact that mammography can only detect approximately $75 \%$ of the prevalent cancers, ultrasound has never been implemented into regular screening trials in order to improve cancer detection. Several studies have shown that detection of breast cancer with mammography is limited in young women and in menopausal women with dense breast tissue [11, 12]. Furthermore, the risk of breast cancer development is highly increased in these patients. A study of more than 200,000 women showed that the breast cancer risk is 5 times increased in case of dense breasts compared to women with involutional changes [12]. Our own observations show that dense breast tissue (American College of Radiology (ACR) 3-4) is found in about 30\% of the menopausal patients. In a clinical setting with curative diagnosis, these patients would routinely receive an additional ultrasound examination. However, in most screening programs, breast density is not even recognized as a predictor for poor mammographic detection and high breast cancer risk. Therefore, mammographic density is often not reported on screening mammograms.

\section{Methods}

The goal of this paper is to discuss the current role and potential future aspects of ultrasound in a curative setting for tumor differentiation and in screening. Therefore, a systematic search of the literature over the last 10 years was performed. Key words were: breast neoplasms, diagnosis, screening, mammography and ultrasound or sonography or ultrasonography. The papers were selected according to equipment quality, investigator experience, relevant number of cases and quality of the study protocol.

\section{Results}

\section{Curative Diagnosis}

The role of breast ultrasound for improved differential diagnosis was investigated over a period of more than 20 years, but case numbers of most studies were small, equipment quality was variable and the diagnostic criteria for lesion descriptions were not standardized. The first large study including 750 patients and using modern high-resolution ultrasound equipment and standardized diagnostic criteria was published by Stavros et al. [4]. In 625 benign and 125 malignant lesions, ultrasound differentiated malignant from benign lesions with a sensitivity of $98.4 \%$ and a negative predictive value of $99.5 \%$. These results were verified in later studies [13, 14]. As a result of these promising findings, the ACR formed an international expert working group in order to evaluate the role of breast ultrasound and to develop standardized diagnostic criteria. In 2003, the ultrasound breast imaging report and data system (BI-RADS) catalogue was published [15]. Based on this classification system of breast lesions, many studies have proven its usefulness [16]. A slight modification in the diagnostic criteria was published in 2006 by a DEGUM (Deutsche Gesellschaft für Ultraschall in der Medizin e.V.) working group together with the German-speaking ultrasound societies ÖGUM (Österreichische Gesellschaft für Ultraschall in der Medizin) and SGUMB (Schweizerische Gesellschaft für Ultraschall in der Medizin und Biologie) [17].

The published data show improved differential diagnosis of breast lesions by ultrasound in addition to mammography (table 1). The sensitivity for cancer diagnosis increases by 10 $20 \%$ with ultrasound in comparison to mammography alone. However, the specificity is more variable [4, 14, 18-20]. In some of the studies, data analysis was stratified by age and showed an inverse correlation between age and accuracy of ultrasound vs. mammography. However, comparisons are difficult as these data are based on retrospective analysis and study protocols were not uniform. But all studies demonstrate 
Table 1. Studies analyzing the efficacy of breast ultrasound

\begin{tabular}{lllllll}
\hline & $\mathrm{n}$ & Cancers & \multicolumn{2}{l}{ Breast ultrasound } & \multicolumn{2}{c}{ Mammography } \\
\cline { 5 - 7 } & & & Sensitivity, \% & Specificity, \% & Sensitivity, \% & Specificity, \% \\
\hline Stavros et al. 1995 [4] & 747 & 125 & 98.4 & 67.8 & 76.8 & - \\
Moss et al. 1999 [18] & 559 & 256 & 88.9 & 77.9 & 78.9 & 82.7 \\
Rahbar et al. 1999 [14] & 161 & 38 & 95.0 & 42.0 & 83.0 & 42.0 \\
Zonderland et al. 1999 [19] & 4,728 & 338 & 91.0 & 98.0 & 67.8 & 75.0 \\
Berg et al. 2004 [20] & 258 & 177 & 83.0 & 34.0 & 87.0 \\
\hline
\end{tabular}

improved accuracy in differentiating benign from malignant breast lesions.

Due to the physics of sound propagation, ultrasound is particularly useful in dense breasts compared with mammography. In contrast, mammography in dense breasts shows almost no tissue details because of the lack of contrast between fibroglandular tissue and soft tissue masses. Ultrasound shows even small lesions with low echogenicity in highly echogenic dense breast tissue. However, ultrasound is more operator dependent than mammography. Therefore, standardization of examination technique and interpretation and quality control of technical standards is essential [21, 22].

Table 1 shows the results of studies analyzing the efficacy of ultrasound for breast lesion characterization in symptomatic patients.

\section{Preoperative Diagnosis, Local Staging}

If breast cancer is suspected or proven by interventional diagnosis, an accurate preoperative planning is essential. Tumor size, localization within the breast, skin and nipple distance or muscle involvement as well as multifocality and multicentricity are important to plan for tumor-adapted surgery or preoperative chemotherapy and follow-up. From the early studies of Holland et al. [23] in the 1980s, it is known that multiple tumor foci and diffuse growth occur in $30-40 \%$ of breast cancers and are underestimated by mammography. This was found by extensive pathological work-up of mastectomy specimens. A few years later, Fornage et al. [24] showed that ultrasound provides an accurate measurement of breast cancer size, with a correlation coefficient between histopathology and ultrasound of 0.84 , and 0.72 for mammography. However, this study did not include diagnosis of multifocal lesions.

In order to improve preoperative local staging and to define the value of ultrasound, we performed a prospective blind study comparing palpation, mammography and ultrasound in 100 patients with breast cancer [25]. Breast cancer was palpable in $83 \%$ of cases, mammography visualized $96 \%$ and ultrasound $98 \%$. Measurement of tumor size showed the highest correlation between histopathology and ultrasound (0.91), for mammography 0.79 , and for palpation 0.77 . Multifocal and multicentric lesions were found in 39 of the cancer patients, whereof ultrasound detected 34 compared to 13 by mammography. Underestimation of total tumor extension, which would have directed to wrong surgical decisions, occurred in $33 \%$ of the mammograms and only in $3 \%$ of the ultrasound examinations [25].

Similar results were found at the same time with contrastenhanced magnetic resonance imaging (MRI) with a high sensitivity for the detection of occult carcinomas [26]. However, disadvantages are the relatively low specificity, low cost effectiveness, the need for injection of contrast agents, difficult localization of MRI-detected lesions, and preoperative interventional assessment. Similar results were also obtained by other studies using ultrasound or ultrasound in combination with MRI, with a detection of additional malignant foci in $27-34 \%$ of breasts not seen after mammography [20, 27-30]. Dynamic MRI is superior to mammography and slightly superior to ultrasound. However, in our own experience, secondlook ultrasound after positive MRI detects many of the masses that were not detected by the primary examination. However, this requires further investigation.

The accurate measurement of tumor extension allows also the use of ultrasound for accurate follow-up measurements in patients receiving neoadjuvant chemotherapy [31]. Ultrasound is also recognized for its ability to provide accurate guidance for interventional procedures [32].

\section{Screening}

According to the first edition of the German S3 guidelines for early breast cancer detection, ultrasound had no role for cancer detection but was only recommended in mammographic BI-RADS IV and V lesions for confirmation and ultrasoundguided interventions [8]. Meanwhile, the literature shows that ultrasound also has a potential for the detection of lesions, especially in women with dense breasts (ACR 2-4). Therefore in the new edition of the S3 guidelines published in 2008, besides mammographic lesions of BI-RADS 4-5, ultrasound is also recommended in BI-RADS 0 and 3 cases and in dense breasts (ACR 3-4) to improve cancer detection and differentiation [32]. The rationale for using ultrasound as an adjunct to mammographic screening to compensate for the reduced sensitivity in dense breasts was described by Berg et al. [33].

An early study with ultrasound for the detection of early breast cancers was already performed 15 years ago [5]. In a prospective study of women without breast symptoms or previous mammography, whole-breast ultrasound was performed 
by a resident supervised in breast ultrasound over a period of 3 months. During the following 3 study months, 1016 women received a whole-breast ultrasound examination. Palpation and mammography were performed after documentation of the ultrasound findings. Four non-palpable carcinomas were detected by ultrasound and only 3 were visible on the following mammogram [5]. In addition, ultrasound detected 32 benign lesions, but only 3 were suspicious while 14 had suspicious mammograms.

Gordon and Goldenberg [6] examined a large population of 12,706 women with normal mammograms and normal clinical findings. Previously detected cancers were not included in this study. Using whole-breast ultrasound, they detected 1575 solid tumors that were not palpable or visible by mammography. In 279 patients $(2.2 \%)$, an interventional diagnosis was performed and 44 cancers were confirmed.

In a similar population of 11,220 women, Kolb et al. again studied ultrasound for cancer detection. They found 3 occult cancers per 1000 breast ultrasound examinations [7]. They selected only women with ACR breast density $2-4(\mathrm{n}=3626)$ in order to reduce the number of ultrasound examinations. Comparison of tumor size with mammographically detected carcinomas showed a similar distribution of early tumor stages. In a following study with a similar protocol including 13,547 patients, they confirmed these results [10]. Dividing the patients in groups with breast density 2, 3 and 4, they found a higher sensitivity of ultrasound and a lower sensitivity of mammography in dense breasts. Besides cancers, Kolb et al. detected other lesions in $6 \%$ and an interventional diagnosis was required in $2.6 \%$.

Buchberger et al. found additional cancers in 4.1 per 1000 ultrasound examinations among 8103 patients which were not detected clinically or by mammography [34]. Additional lesions were found in 5\% of all examinations, and in 3.3\% an interventional diagnosis was required.

A multicentric American College of Radiology Imaging Network (ACRIN) screening study was recently published by Berg et al. [35], comparing ultrasound and mammography in 2637 high-risk patients. 40 participants were diagnosed with cancer. 12 were suspicious on mammography, 8 on both mammography and ultrasound, and 12 on ultrasound alone. 8 women had interval cancers within 12 months. In $8.8 \%$ of the 2637 women, additional lesions were detected by ultrasound and interventional diagnosis was performed in $5.7 \%$. The rate of additional cancers detected with ultrasound was 4.2/1000.

All these studies prove that a significant number of cancers is detected if whole-breast ultrasound is used in addition to mammography, in the order of 3-4/1000 women. However, this increases the number of false positives from $0.3 \%$ in a single-investigator study up to $5.7 \%$ in a multicenter study. But compared with a recall rate of $5-6 \%$ or higher in mammographic screening, this increase is relatively low and may even be lower in follow-up examinations. These additional findings detected by ultrasound will also not increase the number of unnecessary open biopsies, as ultrasound guidance for percutaneous core needle biopsy is the method of choice to make a definitive diagnosis [32].

Indications for breast ultrasound are as follows:

- differentiation of mammographic lesions BI-RADS 0, 3-5;

- palpable lesions: differentiation between cystic/solid and benign/malignant;

- preoperative planning for breast conservation or mastectomy: tumor size, localization, multifocality and multicentricity;

- follow-up measurements of tumor response under neoadjuvant chemotherapy;

- guidance for interventional diagnosis;

- additional breast survey scanning in mammographically dense breasts (ACR 3-4);

- young women $<40$ years and in pregnancy and lactation;

- additional screening in high-risk patients.

\section{Discussion}

Ultrasound has a high diagnostic yield in differentiating breast cancer from benign lesions, in preoperative assessment and even in the detection of early cancers that are mammographically and clinically occult. The advantage of breast ultrasound compared to mammography increases with higher breast density and in young women where the sensitivity of mammography is low. This is an important issue, as dense breast tissue is very common. More than half of the women younger than 50 years have heterogeneously dense $(50-75 \%)$ or very dense $(>75 \%)$ glandular breast tissue [36]. One-third of women older than 50 years have also dense breasts [36] and the sensitivity of mammography in women with dense breasts is as low as $30-48 \%[10,37]$. The interval cancer rate is highly increased in this group [12,37] and, furthermore, dense breast tissue is itself a marker of increased risk of breast cancer in the order of 4-6-fold [12, 38, 39].

Unlike mammography, ultrasound has not been implemented in randomized screening studies, and a mortality reduction with the additional detection of cancers has not been proven. But small cancer size and nodal status are the most important surrogate markers for the quality of screening, and the distribution of cancer size and lymph node status in the ultrasound studies is comparable to mammographic screening-detected invasive cancers [40]. In two counties of Austria, Salzburg and Tirol, mammographic pilot screening studies commenced 2 years ago. The difference compared to the German screening program is that an additional ultrasound examination is offered to patients with increased breast density, and preliminary data demonstrate similar increased detection rates of early cancer stages as in the studies discussed in this paper (Prof. Buchberger, personal communication ).

In this context, it is remarkable that reporting breast density becomes already a legal issue. In the USA state of Con- 
necticut, on October 1, 2009, legislation was signed requiring that patients who undergo mammography are informed about their breast density and that possible additional examinations such as ultrasound or MRI are offered to avoid delay in breast cancer diagnosis.

The main problem of ultrasound is the dependence on different variables [21, 22]. However, good standards were also not established for mammography before screening was implemented in Germany. Scientific bodies such as the International Breast Ultrasound School (www.ibus.org), the ACR (www. acr.org), and the German Ultrasound Society (www.degum.de) have published recommendations to improve qualification and equipment standards which could provide a qualified health service for breast problems in the near future.

\section{Conclusions}

Mammographic screening for breast cancer is important, and it is proven that breast cancer mortality is reduced in the screened population. But mammographic screening does not solve all breast problems. In women with dense breasts, the risk of breast cancer development is increased and sensitivity of mammography is diminished, while ultrasound has much higher sensitivity. Therefore, if mammography is performed, the breast density should always be reported and additional ultrasound should be offered if indicated. Besides improved cancer detection, ultrasound improves the differential diagnosis and local staging and is a useful guidance for interventions.

\section{Acknowledgements}

I wish to acknowledge the assistance of Dr. Ellen Mendelson from the Lynn Sage Breast Center at the Northwestern University of Chicago and Dr. Jack Jellins from the International Breast Ultrasound School for their support in preparing this manuscript, and for their valuable comments that have been instrumental in completing the text.

\section{Conflict of Interest}

The author confirms that there is not conflict of interest.

\section{References}

1 Jackson VP: The current role of ultrasonography in breast imaging. Radiol Clin North Am 1995;33: 1161-1170.

2 Jellins J: Back to the basic raises quality in ultrasound. Diagn Imaging Eur 1999;12-20.

3 Merritt CRB: Future directions in breast ultrasonography. Semin Breast Dis 1999;2:89-96.

$\checkmark 4$ Stavros AT, Thickman D, Rapp CL, et al.: Solid breast nodules: use of sonography to distinguish between benign and malignant lesions. Radiology 1995;196:123-134.

5 Madjar H, Makowiec U, Mundinger A, DuBois A, Kommoss F, Schillinger H: Einsatz der hochauflösenden Sonographie zur Brustkrebsvorsorge. Ultraschall Med 1994;15:20-23.

6 Gordon PB, Goldenberg SL: Malignant breast masses detected only by ultrasound: a retrospective review. Cancer 1995;76:626-630.

7 Kolb TM, Lichy J, Newhouse JH: Occult cancer in women with dense breasts: detection with screening US - diagnostic yield and tumor characteristics. Radiology 1998;207:191-199.

8 Schulz K-D, Albert U-S: Stufe-3-Leitlinie Brustkrebs-Früherkennung in Deutschland. München, Zuckschwerdt, 2003.

$\checkmark 9$ Buchberger W, DeKoekkoek-Doll P, Springer P, Obrist P, Dunser M: Incidental findings on sonography of the breast: clinical significance and diagnostic workup. AJR Am J Roentgenol 1999;173: 921-927.

10 Kolb TM, Lichy J, Newhouse JH: Comparison of the performance of screening mammography, physical examination, and breast US and evaluation of factors that influence them: an analysis of 27,825 patients evaluations. Radiology 2002;225:165-175.

-11 Elmore JG, Armstrong K, Lehmann CD, et al.: Screening for breast cancer. JAMA 2005;293:12451256.
12 Boyd NF, Guo H, Martin LJ, Sun L, Stone J, Fishell E, Jong RA, Hislop G, Chiarelli A, Minkin S, Yaffe MJ: Mammographic density and the risk and detection of breast cancer. N Engl J Med 2007; 356:227-336

13 Skaane P, Engedal K: Analysis of sonographic features in the differentiation of fibroadenomas and invasive ductal carcinoma. AJR Am J Roentgenol 1998;170:109-114.

14 Rhabar G, Sie AC, Hansen GC, Prince JS, Melany ML, Reynolds HW, Jackson VP, Syre JW, Bassett LW: Benign versus malignant solid breast masses: US differentiation. Radiology 1999;213: 889-894.

15 Mendelson EB, Baum JK, Berg WA, Merritt CRB, Rubin E: Breast Imaging Reporting and Data System, BI-RADS: Ultrasound. Reston, American College of Radiology, 2003.

16 Baez E, Strathmann K, Vetter M, Madjar H, Hackelöer BJ: Likelihood of malignancy in breast lesions characterized by ultrasound with a combined diagnostic score. Ultrasound Med Biol 2005; 31:179-184.

17 Madjar H, Ohlinger R, Mundinger A, Watermann D, Frenz JP, Bader W, Schulz-Wendtland R, Degenhardt F: BI-RADS-analogue DEGUM criteria for findings in breast ultrasound - consensus of the DEGUM Committee on Breast Ultrasound. Ultraschall Med 2006;27:374-379.

18 Moss HA, Britton PD, Flower CD, et al.: How reliable is modern breast imaging in differentiating benign from malignant breast lesions in the symptomatic population? Clin Radiol 1999;54:676-682.

19 Zonderland HM, Coerkamp EG, Hermans J, Van De Vijver J, van Voorthuisen AE: Diagnosis of breast cancer: contribution of US as an adjunctive to mammography. Radiology 1999;213:412-422.
20 Berg WA, Gutierrez L, NessAiver MS, Carter WB, Bhargavan M, Lewis RS, Ioffe OB: Diagnostic accuracy of mammography, clinical examination, US, and MR imaging in preoperative assessment of breast cancer. Radiology 2004;233:830-849.

21 Madjar H: The Practice of Breast Ultrasound. Stuttgart, Thieme, 2008.

22 Madjar H, Rickard M, Jellins J, Otto R: IBUS guidelines for the ultrasonic examination of the breast. Eur J Ultrasound 1999;9:99-102.

23 Holland R, Hendricks JHCL, Nravunac M: Mammographically occult breast cancer. A pathologic and radiologic study. Cancer 1983;52:1810-1819.

24 Fornage WD, Toubas O, Morel M: Clinical, mammographic and sonographic dtermination of preoperative breast cancer size. Cancer 1987;60:765771.

25 Madjar H, Ladner HA, Sauerbrei W, Oberstein A, Prömpeler H, Pfleiderer A: Peroperative staging of breast cancer by palpation, mammography and high-resolution ultrasound. Ultrasound Obstet Gynecol 1993;3:185-190.

26 Orel SG, Schnall MD, Powell CM, et al.: Staging of suspected breast cancer: effect of MR imaging and MR-guided biopsy. Radiology 1995;196:115-122.

27 Berg WA, Gilbreath PL: Multicentric and multifocal cancer: whole breast US in preoperative evaluation. Radiology 2000;214:59-66.

28 Moon WK, Noh DY, Im JG: Multifocal, multicentric and contralateral breast cancers: bilateral whole-breast ultrasound in the preoperative evaluation of patients. Radiology 2002;224:569-576.

29 Hlawatsch A, Teifke A, Schmidt M, Thelen M: Preoperative assessment of breast cancer: sonography versus MR imaging. AJR Am J Roentgenol 2002;179:1493-1501. 
30 Liberman L, Morris EA, Dershaw DD, Abramson AF, Tan LK: MR imaging of the ipsilateral breast in women with percutaneously proven breast cancer. AJR Am J Roentgenol 2003;180:901-910.

-31 Seymour MT, Moskovic EC, Walsh G, Trott P, Smith IE: Ultrasound assessment of residual abnormalities following primary chemotherapy for breast cancer. Br J Cancer 1997;76:371-376.

32 Albert US (ed): Stufe-3-Leitlinie BrustkrebsFrüherkennung in Deutschland, 1. Aktualisierung. München, Zuckschwerdt, 2008

33 Berg WA: Rationale for a trial of screening breast ultrasound: American College of Radiology Imaging Network (ACRIN) 6666. AJR Am J Roentgenol 2003;180:1225-1228.
34 Buchberger W, Niehoff A, Obrist P, KoekkoekDoll P, Dunser M: Clinically and mammographically occult breast lesions: detection and classification with high-resolution sonography. Semin Ultrasound CT MR 2000;21:325-336.

35 Berg WA, Blume JD, Cormack JB, Mendelson EB, Lehrer D, et al.: Combined screening with ultrasound and mammography vs mammography alone in women at elevated risk of breast cancer. JAMA 2008;299:2151-2163.

36 Stomper PC, D'Souza DJ, DiNotto PA, Arrendondo MA: Analysis of parenchymal density on mammograms in 1353 women $25-79$ years old. AJR Am J Roentgenol 1996;167:1261-1265.
37 Mandelson MT, Oestreicher N, Porter PL, et al.: Breast density as a predictor of mammographic detection: comparison of interval- and screen-detected cancers. J Natl Cancer Inst 2000;92:1081-1087.

\38 Harvey JA, Bovbjerg VE: Quantitative assessment of mammographic breast density: relationship with breast cancer risk. Radiology 2004;230:29-41.

39 Kerlikowske K: The mammogram that cried Wolfe. N Engl J Med 2007;356:297-300.

40 Nothacker M, Duda V, Hahn M, Warm M, Degenhardt F, Madjar H, Weinbrenner S, Albert US: Early detection of breast cancer: benefits and risks of supplemental breast ultrasound in asymptomatic women with mammographically dense breast tissue. A systematic review. BMC Cancer 2009;20: 335-342. 